University of Nebraska - Lincoln

DigitalCommons@University of Nebraska - Lincoln

Faculty Publications: Department of Entomology

1991

\title{
Mechanisms of Hybrid Sunflower Resistance to the Sunflower Midge (Diptera: Cecidomyiidae)
}

Marc D. Anderson

North Dakota State University

Gary J. Brewer

University of Nebraska-Lincoln, gbrewer2@unl.edu

Follow this and additional works at: https://digitalcommons.unl.edu/entomologyfacpub

Part of the Entomology Commons

Anderson, Marc D. and Brewer, Gary J., "Mechanisms of Hybrid Sunflower Resistance to the Sunflower Midge (Diptera: Cecidomyiidae)" (1991). Faculty Publications: Department of Entomology. 227.

https://digitalcommons.unl.edu/entomologyfacpub/227

This Article is brought to you for free and open access by the Entomology, Department of at DigitalCommons@University of Nebraska - Lincoln. It has been accepted for inclusion in Faculty Publications: Department of Entomology by an authorized administrator of DigitalCommons@University of Nebraska - Lincoln. 


\title{
Mechanisms of Hybrid Sunflower Resistance to the Sunflower Midge (Diptera: Cecidomyiidae)
}

\author{
Department of Entomology, \\ North Dakota State University, \\ Fargo, North Dakota 58105
}

MARC D. ANDERSON AND GARY J. BREWER

\begin{abstract}
J. Econ. Entomol. 84(3): 1060-1067 (1991)
ABSTRACT A study was conducted to identify mechanisms of resistance in sunflower to the sunflower midge, Contarinia schulzi Gagné. Infestation ratings, larval counts, and damage ratings were used to quantify midge resistance in seven sunflower hybrids grown at three locations. Six of the seven hybrids possessed midge resistance. Each hybrid was further categorized with respect to infestation resistance, antibiosis, and tolerance. Two bud characteristics, percent open and size, were examined for their contribution to infestation resistance. The percentage of time that buds of each hybrid were open was negatively correlated with infestation (indicating a preference for the open characteristic). Infestations were higher in buds $\geq 2.5 \mathrm{~cm}$ in diameter. In artificial infestation trials, damage caused by first and second instars was very low due to high larval mortality. When sunflower buds were artificially infested with midge adults, moderate larval infestations occurred. Artificially infesting plants with adults confirmed the presence of antibiosis in two resistant and one susceptible hybrid.
\end{abstract}

KEY WORDS Insecta, Contarinia schulzi, host plant resistance, artificial infestation

THE SUNFLOWER MIDGE, Contarinia schulzi Gagné, is one of a number of pests that cause economic damage to cultivated sunflower (Schulz 1978). Midge biology and damage have been described by Samuelson (1976). Initial damage symptoms consist of small feeding depressions that expand as larval feeding continues. In heavily infested plants, large necrotic pits occur at the base of the bracts and some sunflower hybrids exhibit distortion of the head (capitulum). Head distortion is characterized by an overgrowth of the margins so that the face of the head is concealed. Fertile seed is often absent from heavily damaged heads, especially in the center.

Midge infestations are sporadic and have been reported to depend on temperature and rainfall (Samuelson 1976). In 1982, yield loss was as high as $80 \%$ in some areas (Kopp \& Busacca 1983a). Although damage of this severity has not been encountered since 1982, the potential for economic loss remains.

Since the initial discovery of the sunflower midge as a pest of sunflower (Schulz 1973), differences in resistance among sunflower hybrids have been observed. However, information on the mechanisms of resistance is limited. Fastnaught et al. (1984) indicated that hybrids possessing an open bud type (i.e., bracts spread, exposing the floral disk pad) tended to be more susceptible than the closed bud type.

The purpose of the study reported here was to quantify midge resistance in sunflower hybrids compared to a susceptible control. These hybrids were also used to determine the mechanisms responsible for reduced damage in midge-resistant hybrids. The utility of artificial infestations of sunflower midge larvae and adults for evaluating host resistance was also examined.

\section{Materials and Methods}

Field Trials. Field trials were conducted at three locations in the Red River Valley in 1987: Glenlea and Niverville, Manitoba, and Mapleton, North Dakota. Ten hybrids were planted at Mapletonfour commercial hybrids: 'Northrup King 212', 'Interstate 894', 'Seedtec 315', and 'Seedtec 316'; three experimental hybrids from Dahlgren \& Company, Crookston, Minn.: 'DO-1034E', 'DO643-7E', and 'DO647-7E'; and three hybrids developed by Agriculture Canada: '83-202', '84-108', and '85-346'. Five replicates of four $6-\mathrm{m}$ rows were planted on 13 May in a completely randomized design. A block of 'Interstate 894' was also planted for a source of infested heads and plant material. These $10 \mathrm{hy}$ brids, plus 'Sun M20' (Saskatoon Wheat Pool), were planted at Glenlea. Hybrids at Niverville were: 'Northrup King 212', 'Interstate 894', 'Seedtec 315', 'DO-1304E', 'DO643-7E', 'DO647-7E', '83-202', '84-108', and two additional hybrids from Agriculture Canada, '85-69' and 'NS71 ×266'. The Canadian plots were planted 20 May and were arranged in a randomized complete-block design with five replicates at Glenlea and four replicates at Niverville. Granular trifluralin was applied at $\mathbf{0 . 8 4}$ $\mathrm{kg}[\mathrm{AI}] /$ ha before planting at all three sites.

Beginning during the last week in June, plants were monitored daily at Mapleton for sunflower midge egg masses. Locations were sampled when oviposition was almost complete and larvae were 
still easy to detect. Four to six randomly selected plants per replicate were evaluated for growth stage, bud diameter, and the estimated density of eggs and larvae. Growth stage was assigned according to criteria provided by Schneiter and Miller (1981).

Infestation was determined by gently pulling back bracts and searching for eggs and larvae. Egg density (egg rating $[E R]$ ) was rated using the following scale: 0 , no eggs present; 1 , single eggs scattered sparsely with not more than one small egg mass; 2, two to three small egg masses or one large egg mass; 3 , four to seven small or two to three large egg masses; and 4, more than seven small or three large egg masses. Samuelson (1976) reported that sunflower midge egg masses possess an average of 47 eggs per mass. In our ratings, such an egg mass would be considered small.

Densities of larvae were rated at the same time. Because larvae are often difficult to detect without dissecting the plant, larval ratings $(L R)$ were based on both visible larvae and on evidence of feeding: 0 , no larvae present; 1 , light infestation, very few larvae or very little feeding; 2 , moderate infestation, larvae or larval feeding in two or three isolated areas; 3 , semi-heavy infestation, larvae or larval feeding throughout the bud; and 4, heavy infestation, larvae present in high numbers or extensive larval feeding. Half-values were assigned when egg or larval infestations were intermediate between two whole scores.

Because both eggs and larvae were present on sunflower buds when ratings were taken, neither egg ratings nor larval ratings individually provide an accurate representation of the total infestation. Thus, egg and larval density ratings were combined to give an infestation rating (IR) described by: $I R$ $=E R([4-L R] / 4)+L R$. This formula maintains the original $0-4$ rating scale while reflecting the combined contributions of both the egg and larval scores. The infestation rating is at least equal to the higher of the two contributing scores. The contribution of the lower score diminishes as the higher score increases.

Sunflower midge larvae drop to the soil to pupate when larval development is complete. Larval drop was sampled by placing collection bags on two randomly selected plants per replicate that had previously been evaluated for midge infestation. The collection bags consisted of a cloth drawstring bag with a clear vial attached at the lowest corner. Vials were filled with water to prevent desiccation of larvae. Collection bags were attached $9 \mathrm{~d}$ after the estimated oviposition peak at Mapleton. Collections were made 6,14 , and $35 \mathrm{~d}$ after bagging and the number of larvae $(L N)$ in each sample was recorded. Glenlea was sampled for larval drop once near the end of July, and Niverville was not sampled.

Plants which were rated for egg and larval densities were also rated for damage. Damage ratings (DR) were taken at the $\mathrm{R} 8$ (back of the head yellow, bracts green) growth stage according to the follow- ing scale: 0 , no damage; 1 , light bract damage only, no distortion; 2 , bract damage and light head distortion; 3 , extensive bract damage and head distortion; and 4, severe head distortion with little or no seed production. In cases where the damage was clearly intermediate between two whole ratings, half-values were assigned. A similar rating scale was used by Bracken (1991) and found to correspond closely with yield.

Disk Pad Exposure. Six plants of each hybrid used at the Mapleton plot were planted in the greenhouse, two plants per $30.5-\mathrm{cm}$ pot, using Sunshine Mix no. 1 (Fison's Horticulture, Vancouver, B.C., Canada) as the potting media. Greenhouse conditions were a photoperiod of 16:8 (L:D) and a constant $24^{\circ} \mathrm{C}$. Four of the six plants (randomly assigned) were monitored daily from emergence to R6 (flowering complete) for growth stage, bud diameter, and disk pad exposure.

Disk pad exposure measures the degree to which involucral bracts are spread, exposing the floral disk pad (Fig. 1A and 1B). Disk pad exposure was determined by assigning a " 1 " for the open characteristic, a " 0 " for the closed, and a " 0.5 " when disk pads were partially exposed.

A graph of disk pad exposure ( $y$-axis) versus days after planting ( $\mathrm{x}$-axis) was constructed for each hybrid grown in the greenhouse. The estimated oviposition period ( $6 \mathrm{~d}$ in duration) of sunflower midge females in the field was overlaid on the graph. The location of the oviposition period on the graph was 34-40 d after planting. At this time, sunflowers were at the same growth stage as sunflowers in the field during oviposition. The percentage of time that a bud was open (percent open) during the oviposition period was determined for each hybrid by calculating the area under the disk pad exposure curve in the region bounded by the first and the last day of the overlaid ovipositional period. This area was expressed as a percentage of the total area within the bounded region.

Relative Resistance. Resistance to damage (RD), infestation $(R I)$, antibiosis $(A)$, and tolerance $(T)$ of each hybrid relative to susceptible 'Northrup King 212' was estimated. Because resistance to oviposition, mortality of eggs and first instars, and possible host evasion (Painter 1951) by later developing hybrids could not be separated, all factors resulting in a reduced initial infestation were termed resistance to infestation rather than antixenosis. The following formulas were used to calculate percent $R D, R I, A$, and $T$ for each replicate:

$$
\begin{aligned}
R D_{H}= & \left(1-\left(D R_{H} / D R_{211}\right)\right) \times 100 \\
R I_{H}= & \left(1-\left(I R_{H} / I R_{212}\right)\right) \times R D_{H} \\
A_{H}= & \left(\left(I R_{H} / I R_{212}\right)\right. \\
& \left.-\left(L N_{H} / L N_{212}\right)\right) \times R D_{H} \\
T_{H}= & R D_{H}-\left(R I_{H}+A_{H}\right)
\end{aligned}
$$

$R I$ measures the $R D$ attributable to resistance to infestation. $A$ measures the $R D$ attributable to lar- 

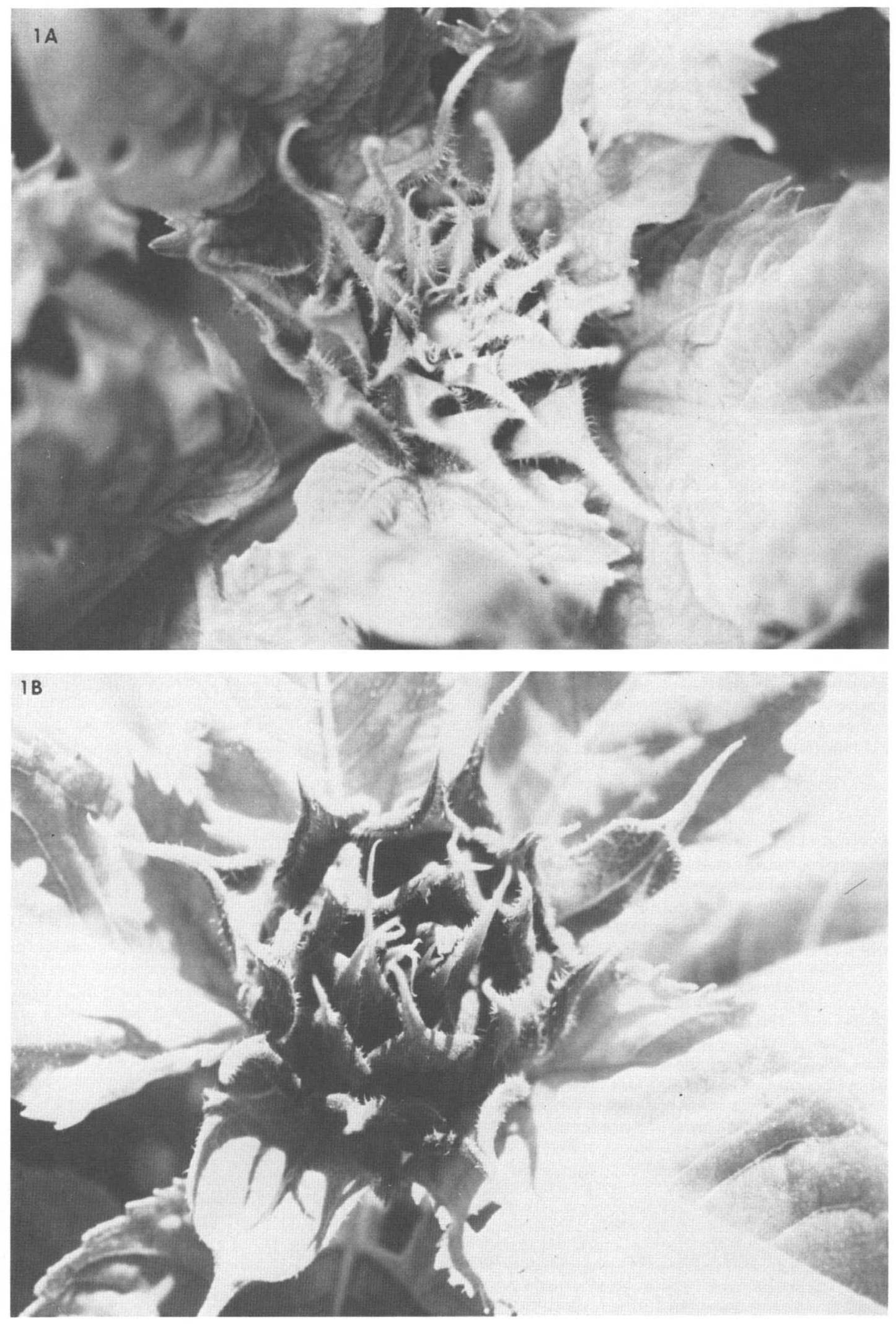

Fig. 1. (A.) Bud of susceptible 'Northrup King 212 ' depicting the open characteristic. (B.) Bud of resistant 'DO647-7E' depicting the closed characteristic. 
val mortality. $T$ is the remaining $R D$ not ascribable to $R I$ or $A$. The subscript $H$ refers to the appropriate rating score of the hybrid in question and the subscript 212 refers to the rating score for 'Northrup King 212'. Because larval counts were not taken from the same plants evaluated for damage, an average $L N_{H}$ was calculated and treated as a constant in the calculation of $A_{H}$. 'Seedtec 316 ', 'Sun M20', '85-346', '85-69', and 'NS71 $\times 266$ ' were not included in these analyses because they were not present at all locations.

Artificial Infestations. Midge-infested heads were collected at Mapleton in 1988 and larvae were extracted by dissecting the infested heads and washing the larvae out with water. Heads were stored at $4^{\circ} \mathrm{C}$ until larvae could be extracted.

All three larval instars were present in the infested heads. Most third instars were separated from first and second instars on a $600-\mu \mathrm{m}$ mesh screen. A 300- $\mu \mathrm{m}$ mesh screen collected second instars and the few third instars that passed through the 600 $\mu \mathrm{m}$ mesh screen. The number of larvae was estimated by counting the larvae on random areas of a grid ( $1 / 15$ of the grid area). Larvae of a given instar were separated into groups of $\approx 200$ and stored in water at $4^{\circ} \mathrm{C}$ until used.

Larvae were applied to plants (late planted) in the field at Mapleton by pouring them onto the center of a sunflower bud. Buds were $3.5-5.0 \mathrm{~cm}$ diameter at the time of infestation. Approximately $2 \mathrm{ml}$ of water was used to transfer and wash the larvae deep within the bracts. Three to five heads of 'Northrup King 212', 'Interstate 894', 'Seedtec 315', 'Seedtec 316', 'DO-1034E', 'DO643-7E', 'DO647-7E', '83-202', '84-108', and '85-346' were infested with $\approx 200$ second instars. The number of replications and date of application varied depending on when plants were in the proper stage and on how many larvae were available. Single heads of 'Northrup King 212', 'Interstate 894', 'Seedtec 315', 'Seedtec 316', 'DO-1034E', 'DO643$7 E$ ', and 'DO647-7E' were infested with $\approx 200$ first instars. Application of $2 \mathrm{ml}$ of water to one plant of each hybrid served as controls. Infested plants were evaluated for damage $23 \mathrm{~d}$ after application of the larvae (after all plants reached R6 [flowering completed]).

Third instars were placed on moist soil in emergence traps, 200 larvae per trap. Each emergence trap consisted of a $250-\mathrm{ml}$ plastic screw-top container with a small, black funnel affixed to the lid. As they emerged, adults were collected in a 16dram vial attached to the end of each funnel. Emergence traps were incubated in a growth chamber with a photoperiod of $18: 6$ (L:D) at $21^{\circ} \mathrm{C}$ for adult emergence.

Adults in each vial were counted and sex was determined. Individual sunflower buds $(3.5-5.0 \mathrm{~cm}$ in diameter) were exposed to 26-34 females and 5-23 males in single-plant cages. Midges were released directly from emergence vials, making it unnecessary to handle each individual manually.
Single-plant adult cages were constructed following the design of Sharma et al. (1988). Two plants of 'Northrup King 212', 'Interstate 894', 'Seedtec 315', and 'Seedtec 316' were exposed to sunflower midge adults at Mapleton. After adults died, cages were removed and infestation ratings were taken.

To collect emerging larvae, cups were attached directly below buds that were artificially exposed to midge adults. Each cup was attached to the plant $11 \mathrm{~d}$ after adult release and was filled with $\approx 50$ $\mathrm{ml}$ of water to prevent desiccation of larvae. Cups were left in place for $10 \mathrm{~d}$ after which larvae were retrieved and counted. Damage ratings of each bud were taken $36 \mathrm{~d}$ after adult release.

Data Analysis. Statistical analysis was performed only on those hybrids present at all locations. 'Northrup King 212', which was used as the susceptible standard, was omitted from the analysis. Infestation and damage ratings within a replicate were averaged and the means were analyzed.

Analysis of variance was computed using the GLM procedure of SAS and means were separated using Tukey's studentized range test (SAS Institute 1985b: 433-506). Two-way analysis of variance was used to determine the significance of hybrid $x$ location interaction for damage rating. Because the interaction was not significant $(F=1.49$; df $=12$, $77 ; P=0.1453$ ), it is felt that comparisons of means over all locations is justified in assessing hybrid resistance. Pooling location variation into the error term by use of one-way analysis of variance resulted in a more conservative means separation. One-way analysis of variance was carried out on all variables. Correlations of mean infestation rating and damage rating with the bud variables, diameter and percent open, were made using the CORR procedure of SAS (SAS Institute 1985a: 861874). Analysis of variance and Tukey's studentized range test were used to compare larval emergence from hybrids exposed to adult midges.

\section{Results and Discussion}

Field Trials. The susceptible standard, 'Northrup King 212', was the most heavily infested and the most severely damaged (Fig. 2) of all hybrids (Table 1). The remainder of the hybrids differed in infestation ( $F=7.81$; $\mathrm{df}=6,91 ; P=0.0001$ ) (Table 1). Infestations in 'Interstate 894' and 'DO643-7E' were moderately heavy, and hybrids 'DO-1034E' and 'Seedtec 315' had the lowest infestation. Significant differences $(F=4.17$; $\mathrm{df}=6$, $91 ; P=0.0010)$ in damage were also observed among hybrids. All hybrids exhibited distortion (ratings greater than 1.0, Table 1) and 'Interstate $894^{\prime}$ exhibited severe head distortion.

Very high numbers of mature larvae dropped from the heads of some hybrids (Table 1). One head of 'Northrup King 212' yielded 5,097 midge larvae. Early larval drop (on or before $15 \mathrm{~d}$ after peak oviposition) occurred in hybrids with mean 


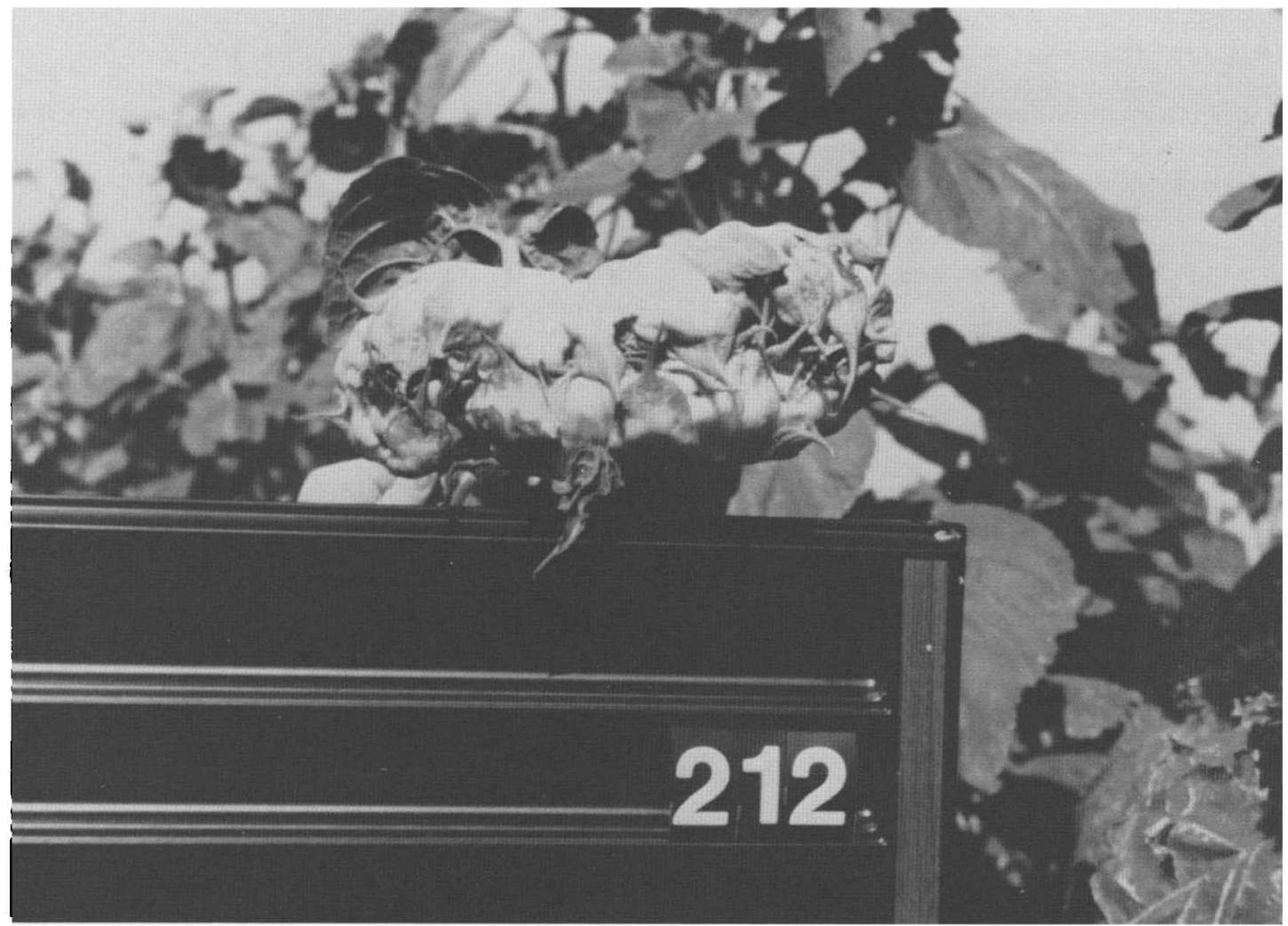

Fig. 2. Susceptible 'Northrup King 212' exhibiting severe midge damage.

larval numbers $>1,000$ ('Northrup King 212' and 'DO643-7E'). Late larval drop (22-43 d after peak oviposition) occurred in hybrids with mean larval numbers <250 ('83-202', 'DO-1034E', and 'Seedtec $\left.315^{\prime}\right)$. Late larval drop may be due to delayed larval development (antibiosis) or to late oviposition in the case of later maturing 'DO-1034E' and 'Seedtec $315^{\prime}$.
Kopp \& Busacca (1983b) reported that large buds were preferred over small buds for oviposition. Among the hybrids tested in this study, variation in bud size was observed $(F=9.76 ; \mathrm{df}=6,91 ; P$ $=0.0001$ ). 'DO-1034E' and 'Seedtec 315 ' were the smallest hybrids and had the lowest infestations. Although mean bud diameters for all hybrids were $>2.5 \mathrm{~cm}$ (Table 1), some individual buds were

Table 1. Sunflower midge infestation and damage ratings, sunflower bud diameters, larval counts, and percent open scores among sunflower hybrids

\begin{tabular}{|c|c|c|c|c|c|c|}
\hline \multirow[b]{2}{*}{ Hybrid } & \multicolumn{4}{|c|}{ Field observations } & \multirow{2}{*}{$\begin{array}{l}\text { Larval counts } \\
\qquad(\mathrm{SD})^{c}\end{array}$} & \multirow[b]{2}{*}{$\%$ Open $^{d}$} \\
\hline & $n$ & $\begin{array}{l}\text { Infestation rating } \\
(\mathrm{SD})^{a}\end{array}$ & $\begin{array}{l}\text { Damage rating } \\
\qquad(\mathrm{SD})^{b}\end{array}$ & Diameter (SD), cm & & \\
\hline Interstate 894' & 14 & $2.15(0.69) \mathrm{ab}^{e}$ & $2.45(0.64) \mathrm{a}^{e}$ & $4.32(1.18) \mathrm{bcd}^{e}$ & $282(283)$ & 22.91 \\
\hline '84-108' & 14 & $1.78(0.63) \mathrm{ab}$ & $1.86(0.51) \mathrm{ab}$ & $4.57(1.36) \mathrm{bc}$ & $505(578)$ & 3.13 \\
\hline$' 83-202^{\prime}$ & 14 & $1.99(0.85) \mathrm{ab}$ & $1.83(0.73) \mathrm{ab}$ & 4.85 (1.13)ab & $257(357)$ & 6.25 \\
\hline 'DO643-7E' & 14 & $2.42(0.85) \mathrm{a}$ & $1.81(0.63) \mathrm{ab}$ & $6.12(1.05) \mathrm{a}$ & $1,096(1,095)$ & 97.92 \\
\hline 'DO-1034E' & 14 & $0.80(0.47) \mathrm{c}$ & $1.64(0.51) \mathrm{b}$ & 3.35 (1.45)ed & $191(162)$ & 0.00 \\
\hline 'Seedtec $315 '$ & 14 & $1.51(0.61) b c$ & $1.58(0.50) \mathrm{b}$ & $3.22(0.94) \mathrm{d}$ & $175(193)$ & 0.00 \\
\hline 'DO647-7E' & 14 & $1.75(0.70) \mathrm{ab}$ & $1.51(0.42) \mathrm{b}$ & $4.73(1.01) b$ & $352(279)$ & 17.71 \\
\hline Northrup King 212'f & 14 & $3.52(0.74)$ & $3.91(0.19)$ & $5.32(1.30)$ & $1,495(1,463)$ & 81.25 \\
\hline
\end{tabular}

${ }^{a} 0$, no infestation; 4 , heavy infestation.

${ }^{b} 0$, no damage; 4 , severe head distortion.

c Number of mature larvae dropping from the head. Mapleton and Glenlea locations only, $n=14-19$.

$d$ Indicates the percentage of time that the floral disk pad is accessible to midge females during the oviposition period (estimated to be $\approx 6 \mathrm{~d}$ long).

e Means within columns followed by common letters are not significantly different $(P<0.05$, Tukey's studentized range test).

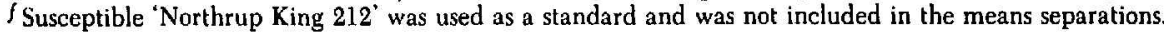


$<2.5 \mathrm{~cm}$ in diameter and were very lightly infested. Individual bud diameters ranged from 1.88 $\mathrm{cm}$ to $8.13 \mathrm{~cm}$ and were positively correlated with infestation $(r=0.440, P=0.001)$ when examined over all hybrids and locations. Because bud diameters were measured at the end of the ovipositional peak, diameters reported in Table 1 may be $0.5-1.0 \mathrm{~cm}$ (about $3 \mathrm{~d}$ growth) larger than when most of the oviposition occurred.

Disk Pad Exposure. Duration of disk pad exposure as well as the time at which exposure occurs may be significant factors in the susceptibility of some hybrids. Open buds may be more attractive to midge females because they allow access for oviposition in the secluded crevices inside the bud. Midge females may also be attracted to the yellow color of the exposed floral disk pad. Values for percent open (percent time that the floral disk pad was exposed during the oviposition period, Table 1) measured in the greenhouse were positively correlated with infestation $(r=0.777, P=0.023)$. Hybrids showing high percent open values in the greenhouse were also observed to be open in the field. Buds of 'Northrup King 212', 'DO643-7E', and 'Interstate 894' (to a lesser extent) were usually open, and were open for a longer duration during the midge oviposition period than the other hybrids in the field.

Oviposition in the center of an open bud would increase the concentration of larvae in the center of the bud relative to the margins. Samuelson (1976) suggested that centrally located larvae are more important in determining the extent of distortion in the sunflower head. However, despite the positive correlation of percent open and infestation, the correlation between percent open and damage was not significant $(r=0.555, P=0.154)$. Antibiosis and tolerance may have obscured the effect of percent open on final head damage by reducing the numbers of larvae or by allowing normal plant growth despite a heavy infestation.

Relative Resistance. Based on the data in Table 1 , the contributions of resistance to infestation, larval antibiosis, and tolerance to the overall resistance of each hybrid were estimated. The scores were made relative to 'Northrup King 212' which had the highest damage and the least resistance in all three categories.

Estimated relative damage resistance for each hybrid is shown in Fig. 3. Each bar is divided into three segments representing the contributions of infestation resistance, antibiosis, and tolerance in each hybrid. 'Northrup King 212', on which resistance designations were based, had an assigned value of zero for each component of resistance. Differences were observed in infestation resistance $(F=8.64 ; \mathrm{df}=6,91 ; P=0.0001)$, antibiosis $(F=$ $7.76 ; \mathrm{df}=6,91 ; P=0.0001)$, tolerance $(F=67.14$; $\mathrm{df}=6,91 ; P=0.0001)$, and relative damage resistance $(F=4.00 ; \mathrm{df}=6,91 ; P=0.0013)$. The major resistance mechanisms in 'Seedtec 315 ' were antibiosis and infestation resistance. 'DO-1034E'

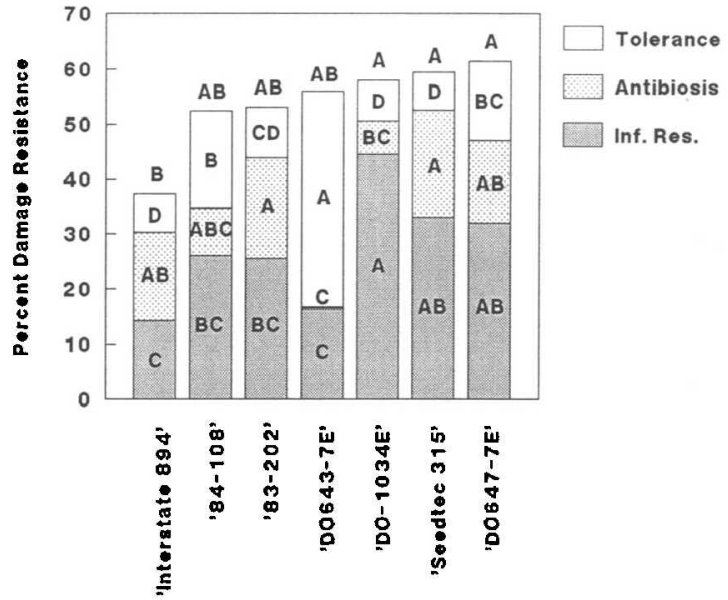

Fig. 3. Percentage damage resistance in nine sunflower hybrids relative to 'Northrup King 212'. Contributions of infestation resistance, antibiosis, and tolerance to each hybrid's damage resistance is depicted within each bar. Within each resistance category, hybrids with different letters are significantly different. Different letters above each bar indicate significant differences in percentage damage resistance.

had a high degree of infestation resistance and the resistance in 'DO643-7E' was mostly tolerance. No one resistance mechanism predominated in 'DO647-7E', '83-202', and '84-108'.

The estimated values for percentage relative damage resistance are essentially inverted damage ratings (Table 1). Hybrids significantly different for percentage relative damage resistance also had significantly different damage ratings. Based on a damage rating of 2.0 or less as delimiting resistance, 'DO647-7E', 'Seedtec 315', 'DO-1034E', 'DO643$7 \mathrm{E}$ ', '83-202', and '84-108' were resistant and 'Interstate 894' was susceptible. The standard, 'Northrup King 212', was considered very susceptible. Of those hybrids not present at all locations, 'Sun M20' was very susceptible, ' $85-346$ ' and ' $85-69$ ' were moderately resistant, and 'Seedtec 316 ' and late-developing 'NS71 $\times 266$ ' were resistant (data not shown). Because the infestation pressure was high in 1987, hybrids classified as resistant should perform adequately in most years.

Artificial Infestations. Although damage occurred, the infestations resulting from larval application were not high enough to induce the degree of distortion observed following natural infestations and necessary for hybrid comparisons. Dead larvae were observed among the bracts and it appeared that they had not moved from the time of application. However, larval feeding was observed in all plants infested with either first or second instars. Buds of water controls of all hybrids were slightly bleached initially, but they recovered their normal appearance after about three days. Thus, the application procedure did not contribute to the damage ratings. Larval damage was limited to the bracts in most hybrids. Head distortion of 
Table 2. Mean infestation and damage ratings and number of larvae collected following application of 200 midge larvae or infesting with adult midges in no-choice cages

\begin{tabular}{|c|c|c|c|c|c|c|c|c|c|}
\hline \multirow{2}{*}{ Hybrid } & \multirow{2}{*}{ Class ${ }^{n}$} & \multicolumn{2}{|c|}{ First instar } & \multicolumn{2}{|c|}{ Second instar } & \multicolumn{4}{|c|}{ Adult } \\
\hline & & $n$ & DR & $\boldsymbol{n}$ & $\mathrm{DR}(\mathrm{SD})$ & $n$ & In (SD) & DR (SD) & $\mathrm{LN}^{b}$ \\
\hline 'Northrup King 212' & VS & 1 & 1.50 & 5 & $1.70(0.76)$ & 2 & $2.25(0.35)$ & $2.25(0.35)$ & $119 a^{c}$ \\
\hline Interstate $894^{\circ}$ & $S$ & 1 & 1.00 & 4 & $0.75(0.29)$ & $\overline{2}$ & $1.50(0.71)$ & $1.50(0.00)$ & $19 b$ \\
\hline 'Seedtec $315^{\prime}$ & $\mathbf{R}$ & 1 & 1.00 & 4 & $0.50(0.00)$ & 2 & $1.50(0.71)$ & $0.75(0.35)$ & $9 b$ \\
\hline 'Seedtec $316^{\prime}$ & $\mathbf{R}$ & $\hat{1}$ & 1.00 & 4 & $1.00(0.00)$ & 2 & $1.25(0.35)$ & $1.00(0.00)$ & $0.5 b$ \\
\hline 'DO-1034E' & $\mathbf{R}$ & 1 & 1.50 & 3 & $1.00(0.00)$ & & & & \\
\hline 'DO643-7E' & $\mathbf{R}$ & 1 & 1.00 & 3 & $1.00(0.00)$ & & & & \\
\hline 'DO647-7E' & $\mathbf{R}$ & 1 & 1.50 & 3 & $1.00(0.00)$ & & & & \\
\hline $83-202$ & $\mathbf{R}$ & & & 3 & $1.00(0.50)$ & & & & \\
\hline$' 84-108^{\prime}$ & $\mathrm{R}$ & & & 3 & $1.33(0.29)$ & & & & \\
\hline$' 85-346^{\prime}$ & MR & & & 3 & $0.67(0.29)$ & & & & \\
\hline
\end{tabular}

a Midge resistance classification. VS, very susceptible; $S$, susceptible; $M R$, moderately resistant; $R$, resistant.

$b$ Larvae caught following adult cage tests.

c Means within columns followed by common letters are not significantly different $(P<0.05$, Tukey's studentized range test).

individual plants was observed only in hybrids 'Northrup King 212', '84-108', and '83-202'. Average damage ratings for all hybrids are given in Table 2.

Approximately $24 \%$ of the third instars placed in emergence traps developed to adults $(77 \% \mathrm{fe}-$ males). Emergence was $83 \%$ complete $13-15 \mathrm{~d}$ after placing the larvae in the emergence traps. Voucher specimens of the emerged adults are in the North Dakota State Insect Reference Collection, Fargo, N.D. Eight specimens of Inostemma sp. (Hymenoptera: Platygasteridae) were collected $22 \mathrm{~d}$ after the majority of midge emergence. These were probably the same species collected by Samuelson (1976), which were thought to be parasites of C. schulzi.

In the adult no-choice trial (Table 2), mean infestation in susceptible 'Interstate 894' was similar to that in resistant 'Seedtec 315' and 'Seedtec 316'. Much of the field resistance in 'Seedtec $315^{\prime}$ ' is attributable to resistance to infestation (Fig. 3). Thus, resistance to infestation in 'Seedtec 315' may be partially due to female choice, which was absent in the no-choice cage test with adults. The small number of larvae collected from 'Interstate 894', 'Seedtec 315', and 'Seedtec 316' compared with 'Northrup King 212' (Table 2) indicates that larval antibiosis is present and supports the estimates of field antibiosis in these hybrids (Fig. 3).

The adult no-choice trial was more effective in causing damage than infesting with larvae. The susceptibility of 'Northrup King 212' and larval antibiosis in 'Interstate 894', 'Seedtec 315 ', and 'Seedtec 316' was confirmed by infesting with adults. The infestation resulting from the release of 26-34 females was lower than observed from the natural population. In future trials, hybrid resistance may be more easily distinguished if more females per cage are used.

The techniques used for artificial infestation would not be practical for screening large numbers of plants, but they do provide a means for determining mechanisms of midge resistance. Larval applications followed by collecting mature larvae and taking damage ratings provide information on antibiosis and tolerance. Adult releases with accompanying infestation ratings, larval counts, and damage ratings provide information on all three components of resistance. No-choice tests more accurately represent agronomic conditions where only one hybrid is available. Artificially infesting buds with either larvae or adults allows the infestation pressure to be varied, so that resistance in sunflower to the sunflower midge can be more completely defined.

\section{Acknowledgment}

The authors thank G. K. Bracken, R. B. Carlson, and L. D. Charlet for their assistance and advice during the course of this study. A portion of this report is part of an M.S. thesis (M.D.A.) submitted to North Dakota State University, Fargo. Partial funding was provided by USDA-CSRS cooperative agreement 84-CRSR-2-2362. Published with the approval of the director of the North Dakota State University, Agricultural Experiment Station as journal series no. 1833 .

\section{References Cited}

Bracken, G. K. 1991. A damage index for estimating yield loss in sunflowers caused by sunflower midge. Can. J. Plant Sci. (in press).

Fastnaught, C. E., J. D. Busacea, \& G. J. Fox. 1984. Host plant resistance/tolerance to the sunflower midge, p. 23. In Proc. Sunflower Res. Workshop. Feb. 1.

Kopp, D. D. \& J. D. Busacca. 1983a. Sunflower midge-1982. ND Farm Res. Bimonthly Bull. 41(2): 3-4.

1983b. Sunflower midge. Cooperative Extension Service Circular E-800. North Dakota State University.

Painter, R. H. 1951. Insect resistance in crop plants. Macmillan, New York.

SAS Institute. 1985a. SAS user's guide: basics. SAS Institute, Cary, N.C.

1985b. SAS user's guide: statistics. SAS Institute, Cary, N.C.

Samuelson, C. R. 1976. Biology and economic importance of Contarinia schulzi Gagné on sunflower cultivars, Helianthus annuus L. in the Red River 
Valley. Ph.D. dissertation, North Dakota State University, Fargo, N.D.

Schneiter, A. A. \& J. F. Miller. 1981. Description of sunflower growth stages. Crop Sci. 21: 901-903.

Schulz, J. T. 1973. Damage to cultivated sunflower by Contarinia schulzi. J. Econ. Entomol. 66: 282.

1978. Insect pests, pp. 169-223. In J. F. Carter [ed.], Sunflower science and technology. American Society of Agronomy, Madison, Wis.
Sharma, H. C., P. Vidyasagar, \& K. Leuschner. 1988. No-choice cage technique to screen for resistance to sorghum midge (Diptera: Cecidomyiidae). J. Econ. Entomol. 81: 415-422.

Received for publication 18 June 1990; accepted 16 January 1991. 